\title{
THE RESPONSE OF CYANOGENIC AND ACYANOGENIC PHENOTYPES OF TRIFOLIUM REPENS TO SOIL MOISTURE SUPPLY
}

\author{
W. FOULDS \\ Science Department, Dudley College of Education \\ and \\ J. P. GRIME \\ Department of Botany, University of Sheffield
}

Received 14.vi.71

\section{INTRODUCTION}

The legumes Trifolium repens $\mathrm{L}$. and Lotus corniculatus L. are represented in many parts of the world by populations in which some or all of the plants are capable of releasing hydrocyanic acid under certain conditions. For both species, there is evidence (Barber, 1955; Jones, 1962) that cyanogenic individuals are less susceptible to grazing by small herbivores.

Cyanogenesis is determined by two independent genes designated $A c$ and $L i$ (Corkill, 1942; Atwood and Sullivan, 1943). The gene $A c$ is dominant and is responsible for the production of two cyanogenic glucosides, lotaustralin and linamarin, which occur in the proportion $4: 1$ (Melville and Doak, 1940). Modifying genes determine the quantity of glucoside produced (Corkill, 1940). The cyanogenic glucosides can be hydrolysed by the $\beta$ glucosidase, linamarase (Coop, 1940) the production of which is governed by the dominant gene $L i$. Hydrolysis yields acetone (from linamarin), methyl-ethyl-ketone (from lotaustralin), glucose, hydrogen cyanide and water. Hughes (1968) maintains that two $\beta$-glucosidases occur in Trifolium repens, one, linamarase of high activity, the other of low activity.

Corkill (1940) showed that individual plants may contain both enzyme and glucoside $(A c L i)$, enzyme only $(a c L i)$, glucoside only $(A c l i)$ or neither (acli). Daday (1954a, b, 1958) measured the contribution of each of the four phenotypes to populations of Trifolium repens sampled on a world scale and found that high frequencies of both $A c$ and $L i$ genes were associated with warm winter conditions. He concluded that in cool climates selection occurs against both genes and showed a close correlation between their frequencies and the January isotherms. For example, a decrease of $1^{\circ} \mathrm{F}$. in January mean temperature was found to correspond to a reduction of 4.23 per cent. in the frequency of the glucoside gene. Daday (1965) has suggested that the mechanism of selection against the cyanogenic property in cold climates is tissue death resulting from irreversible inhibition of respiration by HCN, following the activation of linamarase by low temperatures. It appears that in a normal leaf cell the enzyme and substrate are kept apart although it is not known exactly where each is located. On the basis of experimental evidence Melville and Doak (1940) suggested that the cytoplasm contains 25 per cent. of the lotaustralin and that the remainder is located in the vacuole. According to this hypothesis the vacuolar glucoside would the not be accessible to the enzyme unless damage occurred to the internal membranes of the cell. We may assume, however, that glucoside and enzyme are brought into full contact when the leaf is chewed, crushed or treated 
artificially with reagents such as toluene or chloroform, or when the waterrelations of the cells are disturbed by frosting.

In the light of these facts and theories, we might expect desiccation to be as capable as frosting of releasing $\mathrm{HCN}$ into the tissues and hence of exerting selection against the genes responsible for cyanogenesis. In an attempt to test this hypothesis two approaches are possible. One is to measure the frequency of the genes $A c, a c$ and $L i, l i$ in populations in continuously moist and in droughted habitats. The second approach, which has been adopted in the two experiments described in this paper, is to compare the reaction of cyanogenic and acyanogenic phenotypes to soil moisture stress.

Trifolium repens, the species used in the experiments, is a perennial, stoloniferous herb. In this species competitive ability depends upon both vegetative and sexual reproduction and the relative importance of the two varies with the ecological situation. In measuring response to moisture stress it was necessary therefore to consider both vegetative growth and flowering.

The plants used in both experiments were obtained by propagation of cuttings from plants collected from a population established on a shale path (Rugeley, Staffordshire), containing the four phenotypes, AcLi, Acli, acLi and acli. The phenotypes were distinguished using the picric acid paper technique (Daday, 1954a).

\section{Materials AND MEthods}

\section{Experiment 1}

On 7th June 1969, into each of 32 square garden plots of side $60 \mathrm{~cm}$. was placed four well-rooted plants (one each of the four phenotypes of Trifolium repens). All transplants bore healthy root nodules. The moisture régime of the soil was varied by altering the depth of soil in some of the plots by inserting a continuous polythene sheet at a depth of $5 \mathrm{~cm} ., 10 \mathrm{~cm}$. or $15 \mathrm{~cm}$. In the control treatment no plastic was present and the soil, a fertile sandy loam, exceeded a metre in depth. The plots were arranged in two adjacent $4 \times 4$ latin squares and within each plot the plants were allocated at random to positions on a grid. Each plot was watered initially with $250 \mathrm{ml}$. of Crone's solution (Fred, Baldwin and McCoy, 1932) and this was followed by daily applications of tap-water until 21 st June 1969; subsequently no watering was carried out, and the plants were dependent upon rain.

Soil moisture. In order to compare the conditions of water stress experienced in the four types of plot, soil samples were taken after a period of 7 days without rain. Two samples were removed from each plot from the surface and from a depth of $5-10 \mathrm{~cm}$. The water content was determined by oven-drying at $100 \mathrm{C}$ for 24 hours. The $p \mathrm{H}$ of the soil in each treatment was determined at the beginning and end of the experiment. All replicates were harvested on 12th September 1969. Measurements included the number of fatalities, dry matter production (root and shoot were weighed separately), radial expansion of the shoot, number of plants in flower and number of inflorescences per plant.

\section{Experiment 2}

This experiment was designed to increase the severity of desiccation and to induce a larger number of fatalities. Cuttings of the four phenotypes of 
Trifolium repens (15-17 replicates per phenotype) were grown in 20-cm. pots for 120 days under glasshouse conditions (minimum temperature $20^{\circ} \mathrm{C}$.), with daily watering. At the end of this period the plants were subjected to 4 days without water, then the soil in each pot was thoroughly saturated. This cycle was repeated five times. Dead plants were counted at the end of the experiment.

\section{Results}

\section{Experiment 1}

Measurements confirmed that there was little variation in soil $p \mathrm{H}$ either between treatments or during the course of the experiment (table 1). The mean maximum daily temperature over the whole experimental period was 22.4C. The total rainfall experienced was $194 \mathrm{~mm}$., of which only $12 \mathrm{~mm}$. fell during the first 30 days of the experiment. Determinations carried out during this initial period of drought (table l) showed that there was a progressive decrease in soil moisture content from the deeper to the shallow plots.

TABLE 1

Mean soil $\mathrm{pH}$ and moisture content (during period of drought) of garden plots at varying soil depths

\begin{tabular}{|c|c|c|c|c|}
\hline \multirow[b]{2}{*}{ Soil depth } & \multicolumn{2}{|c|}{ Soil moisture* } & \multicolumn{2}{|c|}{ Soil $p \mathrm{H}^{* *}$} \\
\hline & $\begin{array}{l}\text { Surface } \\
(0-5 \mathrm{~cm} .)\end{array}$ & $\begin{array}{l}5-10 \mathrm{~cm} . \\
\text { depth }\end{array}$ & $\begin{array}{c}\text { Initial } \\
\text { (21.6.69) }\end{array}$ & $\begin{array}{c}\text { Final } \\
(12.9 .69)\end{array}$ \\
\hline $\begin{array}{l}\text { Control } \\
15 \mathrm{~cm} . \\
10 \mathrm{~cm} \\
5 \mathrm{~cm}\end{array}$ & $\begin{array}{r}11.5 \\
7.2 \\
6.0 \\
3.6\end{array}$ & $\begin{array}{r}59 \cdot 0 \\
19 \cdot 0 \\
7 \cdot 2 \\
6 \cdot 0\end{array}$ & $\begin{array}{l}6 \cdot 2 \\
6 \cdot 8 \\
6 \cdot 5 \\
6 \cdot 8\end{array}$ & $\begin{array}{l}6 \cdot 4 \\
6 \cdot 9 \\
6 \cdot 6 \\
7 \cdot 3\end{array}$ \\
\hline
\end{tabular}

* Each value quoted is the mean of 16 measurements and is expressed as percentage water per g. dry soil.

** Each value quoted is the mean of 4 measurements carried out on samples moistened to field capacity.

Fatalities were confined to the plots with $5 \mathrm{~cm}$. of soil and their number did not permit an adequate comparison between phenotypes; out of a possible maximum of eight fatalities for each phenotype the numbers recorded were AcLi two, Acli one, acli one and acLi none.

The diameter of the shoot at harvest (table 2) was directly related to the depth of the soil and each of the four phenotypes produced shoots of small diameter in the plots containing $5 \mathrm{~cm}$. of soil. Although no difference in this respect could be found in the shallow plots, the two ac phenotypes were significantly larger than the two $A c$ phenotypes in the control treatment.

A pattern similar to that obtained for shoot diameter emerges when yield is considered (table 2). In the control plots the ac phenotypes produced greater yields than the $A c$ phenotypes (these were not statistically significant differences however). On the shallow soils there were again no marked differences between the four phenotypes.

With respect to root : shoot ratio (table 2), no significant differences were associated with phenotype suggesting that there is no differential transport of photosynthate to the roots in any of the phenotypes in moist or droughted conditions. 
TABLE 2

Vegetative growth* of four cyanogenic phenotypes of Trifolium repens grown in soils of different depths

\begin{tabular}{|c|c|c|c|}
\hline $\begin{array}{l}\text { Soil depth } \\
\quad(\mathrm{cm} .)\end{array}$ & $\begin{array}{l}\text { Shoot diameter } \\
(\mathrm{cm} .)\end{array}$ & $\begin{array}{l}\text { Dry matter } \\
\text { production } \\
\text { (g.) }\end{array}$ & $\begin{array}{c}\text { Root/shoot } \\
\text { ratio } \\
\text { (by weight) }\end{array}$ \\
\hline \multicolumn{4}{|l|}{$A c L i$} \\
\hline Control & $73 \cdot 5 \pm 15 \cdot 2$ & $14.9 \pm 7.6$ & $0.06 \pm 0.02$ \\
\hline 15 & $54.9 \pm 10.4$ & $8.2 \pm 4.0$ & $0.11 \pm 0.03$ \\
\hline 10 & $44 \cdot 7 \pm 9 \cdot 1$ & $5 \cdot 4 \pm 3 \cdot 0$ & $0.13 \pm 0.03$ \\
\hline 5 & $31 \cdot 6 \pm 13.7$ & $5.0 \pm 7.9$ & $0.22 \pm 0.21$ \\
\hline \multicolumn{4}{|l|}{ Acli } \\
\hline Control & $71 \cdot 6 \pm 12 \cdot 4$ & $14 \cdot 0 \pm 5 \cdot 3$ & $0.05 \pm 0.01$ \\
\hline 15 & $48.5 \pm 9.3$ & $9.6 \pm 5.8$ & $0.08 \pm 0.02$ \\
\hline 10 & $37 \cdot 2 \pm 12 \cdot 8$ & $9.7 \pm 5.5$ & $0.13 \pm 0.03$ \\
\hline 5 & $30 \cdot 2 \pm 16 \cdot 5$ & $6 \cdot 0 \pm 5.4$ & $0.20 \pm 0.12$ \\
\hline \multicolumn{4}{|l|}{$a c L i$} \\
\hline Control & $* * 109.7 \pm 13.8$ & $31 \cdot 0 \pm 12 \cdot 2$ & $0.04 \pm 0.01$ \\
\hline 15 & $67.2 \pm 5.3$ & $8.4 \pm 2.0$ & $0.10 \pm 0.03$ \\
\hline 10 & $44 \cdot 4 \pm 14 \cdot 2$ & $4 \cdot 2 \pm 2 \cdot 0$ & $0.14 \pm 0.03$ \\
\hline 5 & $57 \cdot 0 \pm 25 \cdot 6$ & $11.8 \pm 8.7$ & $0.12 \pm 0.11$ \\
\hline \multicolumn{4}{|l|}{ acli } \\
\hline Control & $94 \cdot 6 \pm 28 \cdot 4$ & $24 \cdot 2 \pm 7 \cdot 1$ & $0.04 \pm 0.01$ \\
\hline 15 & $60 \cdot 8 \pm 15 \cdot 4$ & $11.9 \pm 8.8$ & $0.08 \pm 0.02$ \\
\hline 10 & $53.0 \pm 12.0$ & $8 \cdot 9 \pm 6 \cdot 2$ & $0.12 \pm 0.05$ \\
\hline 5 & $46 \cdot 8 \pm 25 \cdot 8$ & $8.7 \pm 9.9$ & $0.13 \pm 0.05$ \\
\hline
\end{tabular}
plants.

* All measurements were the mean of eight plants.

** The size of this replicate necessitated trailing the runners carefully between nearby

The percentage of plants in flower in the various treatments is illustrated in fig. 1 , which shows that the four phenotypes responded to decreasing soil depth by a reduction in the number of plants which flowered. None of the cyanogenic $(A c L i)$ replicates produced flowers in the $5 \mathrm{~cm}$. or $10 \mathrm{~cm}$. plots and only one of the eight replicates flowered in the $15 \mathrm{~cm}$. and control treatments. All the ac phenotypes flowered in the controls and, at all soil depths, the number of plants in flower was superior to that achieved by the $A c L i$ phenotype. It is interesting to note that the low incidence of flowering is peculiar to the cyanogenic plant and that the Acli phenotype closely resembles the $a c L i$ and acli phenotypes in its performance.

In terms of number of inflorescences per plant at harvest (fig. 1) the cyanogenic $(A c L i)$ plants are inferior in all treatments and again no differences could be recognised between the three remaining phenotypes.

\section{Experiment 2}

The results are presented in table 3 and show that the proportion of fatalities occurring in the $A c$ phenotypes at the end of the five drought cycles was almost three times that of the ac phenotypes $(p<0.01)$.

\section{Discussion}

The experiments described in this paper have involved measurements of drought fatalities and of the vegetative and reproductive vigour of the four phenotypes of Trifolium repens under moist and droughted conditions. When the results are examined evidence can be found of differences between phenotypes with respect to each parameter. It is important to recognise, however, 


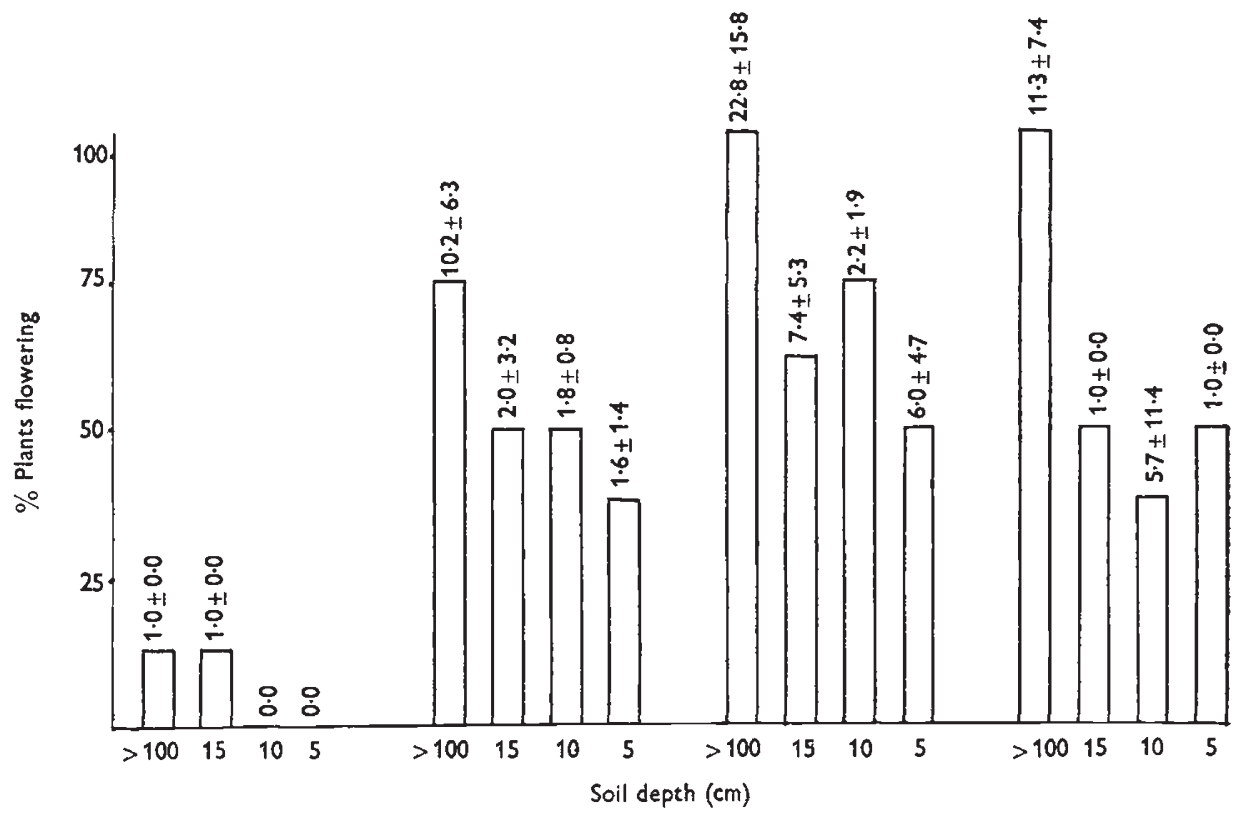

Fig. 1.-Percentage of plants flowering in four cyanogenic phenotypes of Trifolium repens grown in soils of varying depth.

Mean number of inflorescenses per plant with fiducial limits are included above each column.

TABLE 3

Number of fatalities in four phenotypes of Trifolium repens subjected to five drought cycles

$\begin{array}{ccccc}\text { Phenotype } & \text { Dead } & \text { Alive } & \chi_{1}^{2 *} & \text { P } \\ \text { AcLi } & 8 & 8 & 7.92 & <0.01 \\ \text { Acli } & 8 & 7 & - & - \\ \text { acLi } & 3 & 14 & - & - \\ \text { acli } & 3 & 13 & - & -\end{array}$

* $\chi_{1}^{2}$ value is for a $2 \times 2$ contingency table used on a summation of the data for $A c$ and $a c$ phenotypes.

that these differences are of two types. The first includes responses peculiar to the cyanogenic phenotype $(A c L i)$. The second involves differences associated only with $A c / a c$ locus.

Amalgamation of the results of Experiments 1 and 2 reveals that $41 \cdot 7$ per cent. of the AcLi phenotype and 32.1 per cent. of the Acli replicates were killed by drought, but only 12.0 per cent. of the acLi and 16.7 per cent. of the acli plants failed to survive.

It is tempting to ascribe the high mortality of the $A c L i$ phenotypes to the release of HCN following damage to the cells by desiccation. However, it is uncertain whether such a reaction could occur in the Acli phenotypes which do not contain the enzyme necessary for the release of HCN. Alternatively, 
the association of the $A c$ gene with drought sensitivity may be due to linkage between $A c$ and other genes which render the plant susceptible to soil moisture stress. Linkage between the gene $A c$ and genes affecting the vegetative vigour of Trifolium repens is indicated by the results of Experiment 1 where, in the control plots, the ac phenotypes gave higher yields than the $A c$ plants.

From the data it is not possible to establish any causal relationship between the apparent drought sensitivity of the $A c$ phenotypes and their relatively slower rates of growth under conditions of adequate moisture supply (table 2). In Experiment 2, where marked differential mortality was recorded, the time allowed for establishment in pots of moist soil prior to droughting precludes the possibility that the volume of soil exploited by the $A c$ plants was less than that drawn upon by the ac plants. Moreover, in Experiment 1, there were no significant differences either in the production of dry matter or in its partitioning between root and shoot between $A c$ and ac phenotypes harvested from the droughted treatments.

Evidence of an association between the gene $A c$ and drought mortalities has been obtained therefore, but must await both confirmation and elucidation.

Under both moist and droughted conditions in Experiment 1 there is evidence of low sexual reproductive vigour in the cyanogenic plants and it is clearly established that this feature is dependent upon the presence of both glucoside and enzyme genes. Both in terms of the proportion of plants in flower and in the number of inflorescences per plant, the performance of the cyanogenic phenotype is inferior to that of the acyanogenic phenotypes in all treatments. With decreasing soil depth flowering was drastically reduced in each phenotype and in the cyanogenic form the effect of this is to inhibit flowering completely in the most severely droughted treatments. It is interesting to note that Jones (1962) observed that, under field conditions, acli phenotypes of Lotus corniculatus produced more seed than cyanogenic plants growing in a similar environment. Differences in flowering between the phenotypes of Trifolium repens were also noted by Daday (1965), who found that in areas having a high mean winter temperature sexual reproduction in $A c$ phenotypes was superior to that of the $a c$ phenotypes.

We do not know whether the inferior flowering of the cyanogenic phenotype in the present studies is due to pleiotropic effects of the genes $A c$ and $L i$ or to their linkage to genes which influence reproduction.

\section{Summary}

1. Under experimental conditions of severe drought, fatalities in $A c$ phenotypes of Trifolium repens exceeded those in ac phenotypes by a factor of three.

2. Under sublethal moisture stresses the yields of $A c$ and $a c$ phenotypes were not significantly different.

3. In moist conditions ac phenotypes attained higher yields than the $A c$ plants suggesting a possible linkage between the $A c$ gene and genes affecting vegetative vigour.

4. Cyanogenic plants displayed a low sexual reproductive vigour in all treatments and the effect of moisture stress was to inhibit flowering completely 
under conditions in which flowers were produced in all three acyanogenic phenotypes.

Acknowledgments.-We are grateful to $\mathrm{Dr} \mathrm{D}$. A. Jones for supplying quantities of linamarase and to Dr P. S. Lloyd for constructive comments.

\section{REFERENGES}

ATWOod, s. S. AND SULLIVAN J. T. 1943. Inheritance of a cyanogenetic glucoside and its hydrolysing enzyme in Trifolium repens. F. Hered., 34, 311-320.

BARBER, H. N. 1955. The natural history of natural selection. Aust. F. Sci., 18, 148-159.

COOP, I. E. 1940. Cyanogenesis in white clover (Trifolium repens L.). III. A study of linamarase, the enzyme which hydrolyses lotaustralin. N.Z.7. Sci. Tech., 22, 71B-83B.

CoRkILL, L. 1940. Cyanogenesis in white clover (Trifolium repens L.). I. Cyanogenesis in single plants. N.Z.F. Sci. Tech., 22, 65B-67B.

CorkILl, L. 1942. Cyanogenesis in white clover (Trifolium repens L.). V. The inheritance of cyanogenesis. N.Z.F. Sci. Tech., 23, 178B-193B.

DADAY, H. 1954a. Gene frequencies in wild populations of Trifolium repens L. I. Distribution by latitude. Heredity, $8,61-78$.

DADAY, H. $1954 b$. Gene frequencies in wild populations of Trifolium repens L. II. Distribution by altitude. Heredity, $8,377-384$.

DADAY, H. 1958. Gene frequencies in wild populations of Trifolium repens L. III. World distribution. Heredity, 12, 169-184.

DADAY, H. 1965. Gene frequencies in wild populations of Trifolium repens L. IV. Mechanism of natural selection. Heredity, 20, 355-365.

FRED, E. B., BALDWIN, I. L., AND MCCOY, L. 1932. Root Nodule Bacteria and Leguminous plants. University of Wisconsin Press, Madison.

HUGHES, M. A. 1968. Studies on $\beta$-Glucosidase production in cultured tissue of Trifolium repens L. 7. Exp. Bot., 19, 52-63.

JONES, D. A. 1962. Selective eating of the acyanogenetic form of the plant Lotus corniculatus $\mathrm{L}$. by various animals. Nature, 193, 1109.

MELVILLE, F., AND DOAK, B. W. 1940 . Cyanogenesis in white clover (Trifolium repens L.). II. Isolation of the glucosidal constituents. N.Z.F. Sci. Tech., 22, 67B-71B. 